\title{
Problem gambling and family violence: Findings from a population-representative study
}

\author{
NICKI A. DOWLING ${ }^{1,2 *}$, CARRIE EWIN ${ }^{1}$, GEORGE J. YOUSSEF ${ }^{1}$, STEPHANIE S. MERKOURIS $^{1}$, AINO SUOMI ${ }^{3}$, \\ SHANE A. THOMAS ${ }^{4,5}$ and ALUN C. JACKSON ${ }^{2}$ \\ ${ }^{1}$ School of Psychology, Deakin University, Geelong, VIC, Australia \\ ${ }^{2}$ Melbourne Graduate School of Education, University of Melbourne, Parkville, VIC, Australia \\ ${ }^{3}$ Institute of Child Protection Study, Australian Catholic University, Canberra, ACT, Australia \\ ${ }^{4}$ Centre for Research on Ageing, Health \& Wellbeing, Australian National University (ANU), Canberra, ACT, Australia \\ ${ }^{5}$ International Primary Health Care Research Institute, Shenzhen, China
}

(Received: February 19, 2018; revised manuscript received: June 5, 2018; accepted: June 19, 2018)

\begin{abstract}
Background and aims: Few studies have investigated the association between problem gambling (PG) and violence extending into the family beyond intimate partners. This study aimed to explore the association between PG and family violence (FV) in a population-representative sample. It was hypothesized that: (a) PG would be positively associated with $\mathrm{FV}$, even after adjusting for sociodemographic variables and comorbidities and (b) these relationships would be significantly exacerbated by substance use and psychological distress. A secondary aim was to explore whether gender moderated these relationships. Methods: Computer-assisted telephone interviews were conducted with a population-representative sample of 4,153 Australian adults. Results: Moderate-risk (MR)/problem gamblers had a 2.73 -fold increase in the odds of experiencing FV victimization $(21.3 \%$; 95\% CI: 13.1-29.4) relative to nonproblem gamblers $(9.4 \%$; 95\% CI: 8.5-10.4). They also had a 2.56 -fold increase in the odds of experiencing FV perpetration $(19.7 \%$; 95\% CI: $11.8-27.7)$ relative to non-problem gamblers $(9.0 \%$; 95\% CI: $8.0-10.0)$. Low-risk gamblers also had over a twofold increase in the odds of experiencing FV victimization $(20.0 \%$; 95\% CI: $14.0-26.0)$ and perpetration (19.3\%; 95\% CI: 13.5-25.1). These relationships remained robust for low-risk gamblers, but were attenuated for MR/problem gamblers, after adjustment for substance use and psychological distress. MR/problem gamblers had a greater probability of FV victimization, if they reported hazardous alcohol use; and low-risk gamblers had a greater probability of FV perpetration if they were female. Discussion and conclusion: These findings provide further support for routine screening, highlight the need for prevention and intervention programs, and suggest that reducing alcohol use may be important in these efforts.
\end{abstract}

Keywords: problem gambling, intimate partner violence, family violence, victimization, perpetration, psychological distress

\section{INTRODUCTION}

There is limited, but growing, international evidence that problem gambling (PG) is consistently associated with intimate partner violence (IPV), as well as violence that extends beyond intimate partners into the broader family (Dowling, Suomi, et al., 2016). The majority of the available studies of PG and IPV or family violence (FV) have been conducted in treatment-seeking gambling samples (Dowling, Suomi, et al., 2016). In these studies, problem gamblers have reported high rates of past-year IPV victimization (7\%-69\%) (Echeburua, Gonzalez-Ortega, de Corral, \& Polo-Lopez, 2011; Korman et al., 2008; Palmer du Preez et al., 2018; Raylu \& Oei, 2009) and perpetration (31\%-56\%) (Korman et al., 2008; Lorenz \& Shuttlesworth, 1983; Palmer du Preez et al., 2018). Victimization (20\%$64 \%)$ and perpetration $(23 \%-41 \%)$ of violence extending beyond intimate partners is also overrepresented in these treatment-seeking samples (Dowling et al., 2014; Kausch, Rugle, \& Rowland, 2006; Palmer du Preez et al., 2018; Raylu \& Oei, 2009). In FV studies, parents and intimate partners were most likely to be both perpetrators and victims of violence (Dowling et al., 2014; Suomi et al., 2013, 2018).

Samples of gamblers seeking treatment may not be the representative of problem gamblers in the community. Only a small number of studies, however, have been conducted in community-representative studies, all of which have explored the relationship between PG and physical IPV in the US. In these studies, estimates of IPV physical victimization $(4.9 \%-16.1 \%)$ and perpetration $(3.2 \%-23.3 \%)$ in

\footnotetext{
* Corresponding author: Nicki A. Dowling, Associate Professor; School of Psychology, Deakin University, Melbourne Burwood Campus, 221 Burwood Highway, Burwood 3125, Geelong, VIC, Australia; Phone: +61 39244 5610; Fax: +61 39244 6858; E-mail: nicki.dowling@deakin.edu.au.
}

This is an open-access article distributed under the terms of the Creative Commons Attribution-NonCommercial 4.0 International License, which permits unrestricted use, distribution, and reproduction in any medium for non-commercial purposes, provided the original author and source are credited, a link to the CC License is provided, and changes - if any - are indicated. 
problem gamblers are much lower than those identified in treatment-seeking gambling samples (Afifi, Brownridge, MacMillan, \& Sareen, 2010; Bland, Newman, Orn, \& Stebelsky, 1993; Roberts et al., 2016, 2017). To date, however, there are currently no prevalence estimates of FV among problem gamblers in the general community.

Although the exact nature of the relationship between PG and violence within the family is not clearly understood (Dowling, Suomi, et al., 2016), the most commonly held views are that some people, particularly women, employ gambling as a mechanism to physically or emotionally escape IPV or FV victimization, and that gambling may result in stress, anger, and financial crisis, leading to violence perpetration by problem gamblers. Alternatively, it is possible that gambling-related stressors result in chronic family stress and violence perpetration by family members, and that gambling is employed as a coping mechanism consequent to the perpetration of violence by gamblers, a relationship that likely involves alcohol use.

These hypothesized relationships implicate a range of variables, including psychological distress, as well as alcohol and drug use (Dowling, Suomi, et al., 2016). There is some evidence that psychiatric disorders attenuate the associations between PG and both IPV victimization and perpetration (Afifi et al., 2010; Roberts et al., 2016, 2017), although anxiety and depression have not been associated with IPV victimization in problem gamblers (Echeburua et al., 2011). While alcohol- and drug-use problems have generally not influenced the relationship between PG and IPV victimization (Echeburua et al., 2011; Korman et al., 2008; Schluter, Abbott, \& Bellringer, 2008), almost all available studies suggest that alcohol and drug use exacerbate the relationship between PG and IPV perpetration (Brasfield, Shorey, Febres, Strong, \& Stuart, 2011; Brasfield et al., 2012; Goldstein, Walton, Cunningham, Resko, \& Duan, 2009; Muelleman, DenOtter, Wadman, Tran, \& Anderson, 2002). While these findings suggest that psychiatric distress and substance use are likely involved in the relationships between PG and IPV, these variables have not been examined in the association between $\mathrm{PG}$ and FV, more broadly.

Gender is also implicated in these hypothesized relationships. Most available findings suggest there are no gender differences in IPV or FV victimization or perpetration in treatment-seeking problem gamblers (Korman et al., 2008; Suomi et al., 2018) and that gender fails to moderate the relationship between PG severity and IPV perpetration in community samples (Afifi et al., 2010). There are, however, some equivocal findings, whereby female problem gamblers have been more likely than men to report IPV injury perpetration (Korman et al., 2008), FV perpetration (Palmer du Preez et al., 2018), as well as IPV victimization (Palmer du Preez et al., 2018) and FV victimization (Dowling et al., 2014; Palmer du Preez et al., 2018) than male problem gamblers.

Understanding the relationship between PG and violence that extend beyond intimate partners into the broader family has important public health implications. To date, however, this relationship has not been explored in a community-representative study. Therefore, this study aimed to explore the nature of the association between PG and FV (victimization and perpetration) in a populationrepresentative sample. It was hypothesized that: (a) PG would be positively associated with FV, even after adjusting for sociodemographic variables and comorbidities (hazardous alcohol use, cannabis use, other substance use, and psychological distress); and (b) the relationships between PG and FV would be significantly exacerbated by these comorbid conditions. Given the available equivocal findings, a secondary exploratory aim was to explore whether gender moderated these relationships.

\section{METHODS}

\section{Participants}

Data were collected from a computer-assisted telephone interview of a sample of 4,153 Australian adults $(2,022$ men, 48.7\%). Participants were aged 18-29 years (13.8\%), $30-44$ years $(35.2 \%), 45-64$ years $(29.9 \%)$, and $65+$ years (21.2\%). Most participants were cohabiting (64.5\%), were born in Australia (79.6\%), and were employed (59.3\%).

\section{Measures}

PG was assessed using the 9-item Problem Gambling Severity Index (PGSI; Ferris \& Wynne, 2001). PGSI scores can be classified into non-PG (NPG) $($ score $=0)$, low-risk gambling $(\mathrm{LRG})$ (score $=1-2)$, moderate-risk $(\mathrm{MR})$ gambling (score $=3-7$ ), and PG (score $=8-27$ ). The HurtInsult-Threaten-Screamed Scale (HITS; Sherin, Sinacore, Li, Zitter, \& Shakil, 1998) was modified into two single items, binary screening instruments to measure whether the participant had experienced FV victimization and perpetration in the past year, and participants who positively endorsed each item were asked to identify the family member/s. The Alcohol Use Disorders Identification TestC (AUDIT-C; Saunders, Aasland, Babor, De La Fuente, \& Grant, 1993) was employed to measure hazardous alcohol use, which is indicated by a cut-off score of 4 . The second item of the Alcohol, Smoking, and Substance Involvement Screening Test (ASSIST; World Health Organization ASSIST Working Group, 2002) was employed to determine frequency of cannabis or other substance use (cocaine, amphetamines, inhalants, sedatives, hallucinogens, and opioids) in the past 3 months. Finally, the Kessler Psychological Distress Scale (K10; Kessler \& Mroczek, 1992) was used to measure current (1 month) psychological distress. Using the scoring based on Australian norms, K10 scores can be categorized as low (score $=10-15)$, moderate (score $=$ $16-21)$, high $($ score $=22-29)$, and very high $($ score $=30-50)$ (Andrews \& Slade, 2001).

\section{Procedure}

The data were collected by independent market research providers using a targeted random digit dialing telephone survey methodology. The in-scope population was Australian residents aged 18 years and above who were contactable by a landline telephone. Incremental sampling with quota allocation was used to ensure adequate numbers of the target 
groups. A maximum of 10 contacts were attempted in the event of a live number. The $\chi^{2}$ goodness-of-fit tests for age and gender revealed no significant differences between the study sample and the Australian population.

\section{Statistical analyses}

Missing data ranged from $0 \%$ to $13 \%$ (cannabis use), but significant intercorrelations between all variables in the data set provided evidence for a missing at random (MAR) pattern. Consequently, missing data were managed using multiple imputations with chained equations, which are appropriate when data are MAR (Enders, 2010). Specifically, 50 imputed data sets were created using all analysis variables, and final results (i.e., proportions and regression effects) were based on pooled estimates using Rubin's (1987) rules. Due to substantial positive skew in PGSI PG severity, K10 psychological distress, and AUDIT-C hazardous alcohol-use variables, these were recategorized to represent ordinal categories [i.e., PGSI: NPG, LRG, $\mathrm{MR} / \mathrm{PG}$; and K10: low, moderate, and high/very high] or binary categories (i.e., AUDIT-C: dichotomized based on the cut-off score).

Given that early evidence from retrospective accounts suggests that PG generally precedes, or coincides with, both victimization and perpetration (Suomi et al., 2013, 2018), each FV outcome variable (victimization and perpetration) was regressed on to PGSI PG severity in a series of separate binary logistic regressions, adjusting for (a) gender, age, and employment status; (b) gender, age, employment status, and substance use (hazardous alcohol use, cannabis use, and other substance use); (c) gender, age, employment status, and psychological distress; and (d) all previous adjustment variables. In a separate set of analyses, the degree to which the associations between PGSI PG severity and FV victimization and perpetration were moderated by hazardous alcohol use, cannabis use, other substance use, psychological distress, or gender were examined. For each moderation analysis, the outcome variable (victimization and perpetration) was regressed on the interaction term and the two main effects terms while controlling for gender, age, and employment status.

\section{Ethics}

The study procedures were carried out in accordance with the Declaration of Helsinki and were approved by the Monash University Human Research Ethics Committee (CF07/3951). All participants provided informed consent.

\section{RESULTS}

The total sample comprised 92.6\% [95\% CI: 91.7, 93.4] NPG, $4.9 \%$ [95\% CI: 4.2, 5.5] LRG, and 2.6\% [95\% CI: 2.1 , 3.1] $\mathrm{MR} / \mathrm{PG}$. Of the entire sample, $17.7 \%$ [95\% CI: 16.5 , 18.8] reported no gambling participation in the prior 12 months. The FV victimization rate for the whole sample was $10.3 \%$ [95\% CI: 9.3, 11.3], whereas the FV perpetration rate was $9.8 \%$ [95\% CI: 8.8, 10.7]. The total sample also comprised $27.7 \%$ [95\% CI: $26.3,29.1]$ classified as having hazardous alcohol use, 5.4\% [95\% CI: 4.7, 6.2] who endorsed cannabis use, and 10.2\% [95\% CI: 9.2, 11.1] who endorsed other drug use. With respect to psychological distress, $81.4 \%$ [95\% CI: 80.2, 82.6] were classified in the low range, $12.5 \%$ [95\% CI: $11.4,13.6]$ were classified in the moderate range, and $6.1 \%$ [95\% CI: 5.3, 6.8] were classified in the high/very high range.

Table 1 reveals that both MR/PGs and LRGs had a 2.56to 2.73-fold increase in the odds of experiencing both FV victimization $(20 \%-21.3 \%)$ and perpetration $(19.3 \%$ $19.7 \%$ ), after controlling for gender, age, and employment status, relative to NPGs $(9.0 \%-9.4 \%)$ (Model 1). These relationships were robust for LRGs, but were generally attenuated for MR/PGs, to the adjustment for substance use (hazardous alcohol use, cannabis use, and other substance use; Model 2), and psychological distress (Model 3). In the final multivariable model (Model 4), the effect for MR/PGs (relative to NPGs) was attenuated in both the FV victimization and perpetration models with results suggesting the observed effects were not inconsistent with the null hypothesis after controlling for all variables.

Table 2 reveals that fathers were most likely to be perpetrators of violence toward $\mathrm{MR} / \mathrm{PGs}$, but compared to those of NPGs, both fathers $\left[\chi^{2}(1)=16.65, p<.001\right]$ and male in-law relatives $\left[\chi^{2}(1)=8.44, p=.004\right]$ of $\mathrm{MR} / \mathrm{PGs}$ were more likely to be perpetrators. In contrast, intimate partners and female in-laws were most likely to be the victims of violence perpetrated by $\mathrm{MR} / \mathrm{PGs}$. Compared to those of NPGs, children $\left[\chi^{2}(1)=5.02, p=.025\right]$ of MR/PGs were less likely to be victims, whereas fathers $\left[\chi^{2}(1)=\right.$ 7.633, $p=.006]$, male in-law relatives $\left[\chi^{2}(1)=12.61\right.$, $p<.001]$, and female in-law relatives $\left[\chi^{2}(1)=123.00\right.$, $p<.001]$ of MR/PGs were more likely to be victims.

Only hazardous alcohol use moderated the relationship between PGSI PG severity and FV victimization $\left[\chi^{2}(2)=\right.$ 4.26, $p=.014]$. Figure 1 reveals that MR/PGs had greater probability of experiencing $\mathrm{FV}$ victimization, if they were in the hazardous alcohol use category compared to the nonhazardous category; moreover, the magnitude of this difference was strong [risk difference $=25 \%, t(1)=2.94$, $p=.003]$. In addition, only gender moderated the relationship between PGSI PG severity and FV perpetration $\left[\chi^{2}(2)=3.03, p=.048\right]$. Figure 1 reveals that LRGs had greater probability of FV perpetration, if they were females compared to males; moreover, the magnitude of this difference was strong [risk difference $=22 \%, t(1)=3.37$, $p=.001]$.

\section{DISCUSSION}

In this population-representative sample, MR/PGs had over a twofold increase in the odds of experiencing both FV victimization $(21.3 \%)$ and perpetration $(19.7 \%)$ relative to non-problem gamblers, although the estimates in this study are the lower end of the range obtained previously in nonrepresentative samples (Dowling et al., 2014; Kausch et al., 2006; Palmer du Preez et al., 2018; Raylu \& Oei, 2009). This finding is not unexpected given that representative samples display less severe gambling problems and a lower variety and intensity of comorbid psychiatric 
Table 1. Adjusted odds ratio (aOR) estimates (pooled) for PGSI problem gambling categories predicting family violence victimization and perpetration $(N=4,153)$

\begin{tabular}{|c|c|c|c|c|c|}
\hline PGSI category & $\%[95 \% \mathrm{CI}]$ & $\begin{array}{l}\text { aOR - Model } 1 \\
{[95 \% \mathrm{CI}]}\end{array}$ & $\begin{array}{l}\text { aOR - Model } 2 \\
{[95 \% \mathrm{CI}]}\end{array}$ & $\begin{array}{c}\text { aOR - Model } 3 \\
{[95 \% \mathrm{CI}]}\end{array}$ & $\begin{array}{l}\text { aOR - Model } 4 \\
{[95 \% \mathrm{CI}]}\end{array}$ \\
\hline \multicolumn{6}{|c|}{ FV victimization $[n=428(10.3 \% ; 95 \% \text { CI: } 9.3,11.3)]^{\mathrm{a}}$} \\
\hline $\begin{array}{l}\text { Non-problem gambling } \\
\quad(n=3,844)\end{array}$ & $9.4[8.5-10.4]$ & 1 & 1 & 1 & 1 \\
\hline $\begin{array}{l}\text { Low-risk gambling } \\
(n=202)\end{array}$ & $20.0[14.0-26.0]$ & $2.66[1.77-4.02]^{* *}$ & $2.76[1.82-4.18]^{* *}$ & $2.48[1.63-3.76]^{* *}$ & $2.57[1.68-3.93]^{* *}$ \\
\hline $\begin{array}{l}\text { Moderate-risk/problem } \\
\text { gambling }(n=107)\end{array}$ & $21.3[13.1-29.4]$ & $2.73[1.63-4.56]^{* *}$ & $2.29[1.35-3.89]^{* *}$ & $1.87[1.09-3.19]^{*}$ & $1.58[0.91-2.75]$ \\
\hline \multicolumn{6}{|c|}{ FV perpetration $[n=407(9.8 \% ; 95 \% \text { CI: } 8.8,10.7)]^{\mathrm{a}}$} \\
\hline $\begin{array}{l}\text { Non-problem gambling } \\
\quad(n=3,844)\end{array}$ & $9.0[8.0-10.0]$ & 1 & 1 & 1 & 1 \\
\hline $\begin{array}{l}\text { Low-risk gambling } \\
(n=202)\end{array}$ & $19.3[13.5-25.1]$ & $2.70[1.78-4.07]^{* *}$ & $2.63[1.73-3.99]^{* *}$ & $2.51[1.65-3.82]^{* *}$ & $2.47[1.62-3.77]^{* *}$ \\
\hline $\begin{array}{l}\text { Moderate-risk/problem } \\
\text { gambling }(n=107)\end{array}$ & $19.7[11.8-27.7]$ & $2.56[1.50-4.36]^{* *}$ & $2.17[1.26-3.74]^{* *}$ & $1.92[1.11-3.31]^{*}$ & $1.63[0.93-2.87]$ \\
\hline
\end{tabular}

Note. aOR (Model 1): adjusted for gender, age, and employment status; aOR (Model 2): adjusted for gender, age, employment status, hazardous alcohol use, cannabis use, and other substance use; aOR (Model 3): adjusted for gender, age, employment status, and psychological distress; aOR (Model 4): adjusted for gender, age, employment status, hazardous alcohol use, cannabis use, other substance use, and psychological distress; PGSI: Problem Gambling Severity Index; CI: confidence interval; FV: family violence.

aEstimates pooled over 50 imputations; FV victimization HITS item: "In the past 12 months, has a family member physically hurt you, insulted or talked down to you, threatened you with harm, or screamed or cursed at you?" and FV perpetration HITS item: "In the past 12 months, have you physically hurt, insulted or talked down to, threatened with harm, or screamed or cursed at a family member?" ${ }^{*} p<.05 .{ }^{* *} p<.01$.

Table 2. Crosstabulation of PGSI problem gambling categories and family violence perpetrators/victims ${ }^{\mathrm{a}}$

\begin{tabular}{|c|c|c|c|}
\hline & $\begin{array}{l}\text { Non-problem gambling } \\
\qquad(n=3,844)\end{array}$ & $\begin{array}{l}\text { Low-risk gambling } \\
\qquad(n=202)\end{array}$ & $\begin{array}{c}\text { Moderate-risk/problem } \\
\text { gambling }(n=107)\end{array}$ \\
\hline \multicolumn{4}{|c|}{ Perpetrators of FV toward the respondent (\%) } \\
\hline Intimate partner & 29.4 & 26.4 & 23.8 \\
\hline Child & 26.6 & 11.8 & 23.8 \\
\hline Sibling & 20.6 & 38.2 & 23.8 \\
\hline Mother & 9.8 & 29.4 & 9.5 \\
\hline Father & 8.5 & 8.8 & 33.3 \\
\hline Male in-law & 5.1 & 5.9 & 19.0 \\
\hline Female in-law & 3.5 & 2.9 & 4.8 \\
\hline Other & 4.7 & 5.9 & 0.0 \\
\hline \multicolumn{4}{|c|}{ Victims of FV perpetrated by the respondent (\%) } \\
\hline Intimate partner & 26.0 & 24.2 & 26.3 \\
\hline Child & 46.7 & 12.1 & 21.1 \\
\hline Sibling & 18.0 & 48.5 & 10.5 \\
\hline Mother & 12.0 & 30.3 & 10.5 \\
\hline Father & 6.0 & 12.1 & 21.1 \\
\hline Male in-law & 1.3 & 3.0 & 10.5 \\
\hline Female in-law & 1.0 & 3.0 & 26.3 \\
\hline Other & 3.0 & 9.1 & 0.0 \\
\hline
\end{tabular}

Note. PGSI: Problem Gambling Severity Index; FV: family violence.

${ }^{a}$ Using raw (non-imputed) data.

disorders compared with their treatment-seeking counterparts (Crockford \& el-Guebaly, 1998; Slutske et al., 2001). Moreover, the rates of $\mathrm{FV}$ victimization and perpetration were low (approximately 10\%) across the whole sample in this study. The relatively low rates of FV in LRGs and PGs are, however, consistent with previous FV treatmentseeking gambling studies that have employed current measures of physical and emotional (psychological) abuse (but not sexual or financial abuse) (Dowling et al., 2014; Raylu \& Oei, 2009). Interestingly, LRGs also had over a twofold increase in the odds of experiencing both FV victimization $(20.0 \%)$ and perpetration $(19.3 \%)$, confirming that prevention efforts to reduce even minor gambling problems is necessary (Afifi et al., 2010). Although intimate partners of 

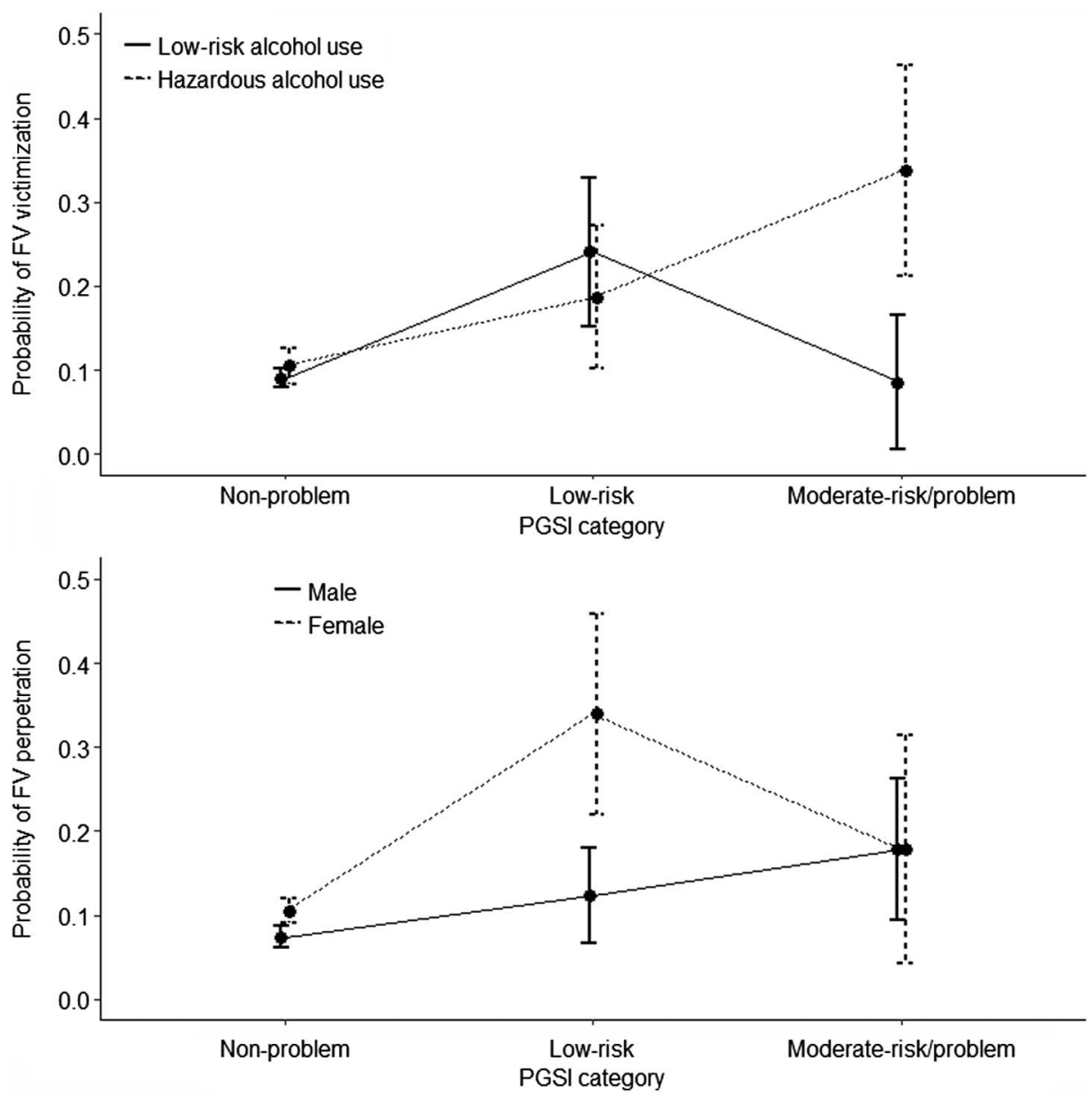

Figure 1. Interaction effects of PGSI category and hazardous comorbidities/gender in predicting FV victimization/perpetration

MR/PGs were among the most likely to be perpetrators and victims of violence, non-intimate partner family members, particularly fathers and male in-law relatives, were overrepresented as both victims and perpetrators, suggesting that these family members may be important in understanding the nature of the relationship between PG and FV.

The effect sizes representing the odds of experiencing FV were similar to LRGs and MR/PGs when controlling for sociodemographic characteristics. These relationships generally remained robust to adjustment for substance use and psychological distress for LRGs. Consistent with previous research (Afifi et al., 2010; Roberts et al., 2016, 2017), however, these associations were attenuated for MR/PGs, after controlling for these comorbidities, particularly psychiatric distress. In fact, the effect for MR/PGs was no longer significant for either FV victimization or perpetration after controlling for both substance use and psychiatric distress. Although this specific finding may be somewhat an artifact of underpowered models, resulting from the relatively low prevalence of MR/PGs in this general population sample, it suggests that these comorbidities are more important than PG in explaining FV in MR/PGs. This is not surprising given that both substance use and psychological distress are consistently related to $\mathrm{FV}$ victimization and perpetration (Abramsky et al., 2011; Capaldi, Knoble, Shortt, \& Kim, 2012; Dowling et al., 2017; World Health Organization [WHO], 2002). Moreover, substance use is consistently associated with PG (Dowling et al., 2015, 2017), whereas psychological distress is a common feature of a subsample of problem gamblers (Dowling et al., 2017; Scholes-Balog, Hemphill, Toumbourou, \& Dowling, 2015; Suomi, Dowling, \& Jackson, 2014).

Interestingly, hazardous alcohol use by MR/PGs exacerbated the risk of the victimization of violence by family members. This finding is not unexpected, given the central role of alcohol consumption plays in shaping the extent and impact of gambling behavior (Dowling et al., 2015, 2017) and IPV (WHO, 2006). For example, alcohol use may increase the likelihood of gambling by reduced control, exacerbate gambling losses and related consequences, reduce capability to negotiate a non-violent resolution, and exacerbate other family stressors (WHO, 2006). Although no other comorbidity significantly moderated the relationships between PG and FV perpetration, there may be any number of potential relationships between these comorbidities, gambling behavior, and FV. Alternatively, they may be associated with only some types of violence, or their moderating effect may have been diluted by the measurement of violence involving non-intimate partner family members. Further research is required to elucidate the proximal relationships between these variables.

Consistent with some limited previous research (Korman et al., 2008; Palmer du Preez et al., 2018), LRGs had a greater probability of FV perpetration if they were females 
compared to males. These findings suggest that women are more likely perpetrate violence against their LRG family member, probably as an early response to emerging gambling-related stressors (Dowling, Suomi, et al., 2016). Although controversial, there is considerable evidence that women are more likely than men to use physical aggression against their intimate partners (Archer, 2000). These findings, however, likely reflect the use of an acontextual actsbased approach to the measurement of violence, which may narrowly frame violence as gender-neutral "conflict" that fails to reach the threshold linked to poor health outcomes (Ford-Gilboe et al., 2016). Future research in the gambling field is required to explore the role of gender using measurement that considers the cultural, historical, and gendered context in which the violence occurs.

Study limitations include the cross-sectional design, which does not allow for inferences regarding temporal or causal associations among variables, the sampling of relatively small numbers of problem gamblers, and the variable measurement timeframes of the measures employed in this study. Moreover, although they were employed because there are currently no brief standardized FV screening instruments (Rabin, Jennings, Campbell, \& Bair-Merritt, 2009), the modified HITS items fail to differentiate between violence types, measure purely acontextual acts, exclude some FV elements, and have unknown classification accuracy. The non-coverage of "mobile telephone-only" households by traditional landline sampling methods may also have introduced a source of bias (Dowling, Jackson, et al., 2016; Jackson, Pennay, Dowling, Coles-Janess, \& Christensen, 2014), although only a relatively small proportion of Australian adults (approximately 13\%) lived in mobile-phone-only households during the survey (Australian Communications and Media Authority, 2015). Studies using large samples, measures with consistent timeframes, standardized brief instruments, and dual frame methodologies will methodologically improve future studies in this important area of research. Moreover, longitudinal analyses are required to explicate the degree to which there is a cyclical process in which one behavior serves to exacerbate the other and the degree to which comorbidities such as substance use and psychological distress are underlying causal mechanisms (Dowling, Suomi, et al., 2016).

Despite these limitations, this study extends our understanding of the violence that occurs in families beyond intimate partners across the full spectrum of PG severity (Dowling, Suomi, et al., 2016). The findings provide further support for routine screening of FV in PG services and PG in IPV services, highlight the need for prevention and intervention programs to lower the risk of the co-occurrence of these behaviors, and suggest that reducing alcohol use may be important in these efforts.

Funding sources: This study provides an unfunded secondary analysis of data collected for the Children at Risk Study funded by Gambling Research Australia (tender number 103/06).
Authors' contribution: NAD conceptualized this study. NAD, ACJ, SAT, and AS developed the methodology. NAD and CE prepared the first draft of the manuscript. NAD wrote the final draft of the manuscript. GJY and SSM conducted the statistical analysis. SAT coordinated the CATI survey reported in this study. All authors contributed to and have approved the final version of the manuscript. NAD affirms that she had access to all data from the study, both what was reported and what was unreported, and also that she had complete freedom to direct its analysis and its reporting, without influence from the sponsors. She also affirms that there was no editorial direction or censorship from the sponsors. NAD and CE share equal first authorship.

Conflict of interest: All authors report no financial or other relationships and no conflict of interest relevant to the subject of this article. Consistent with the common standard for conflict of interest disclosure in addiction research, the following statement reports any potential conflicts of interest over the past 3 years (dating from the month of submission). NAD, SSM, AS, GJY, SAT, and ACJ have received funding from multiple sources, including government departments or agencies that are primarily funded by government departments (some through hypothecated taxes from gambling revenue). NAD, SSM, and GJY have received funding from the National Association for Gambling Studies (NAGS), a not-for-profit, self-funding organization that derives its funding from member fees and conference proceeds. SSM has been the recipient of the NAGS student presentation award and NAD and SSM have been the Victorian state representatives of the NAGS National Committee, on an unpaid basis. CE is the recipient of a Research Training Program (RTP) Scholarship funded by the Australian Government. None of the authors have knowingly received research funding from the gambling industry or any industry-sponsored organization.

\section{REFERENCES}

Abramsky, T., Watts, C. H., Garcia-Moreno, C., Devries, K., Kiss, L., Ellsberg, M., Jansen, H. A. F. M., \& Heise, L. (2011). What factors are associated with recent intimate partner violence? Findings from the WHO multi-country study on women's health and domestic violence. BMC Public Health, 11(1), 109-125. doi:10.1186/1471-2458-11-109

Afifi, T. O., Brownridge, D. A., MacMillan, H., \& Sareen, J. (2010). The relationship of gambling to intimate partner violence and child maltreatment in a nationally representative sample. Journal of Psychiatric Research, 44(5), 331-337. doi:10.1016/j.jpsychires.2009.07.010

Andrews, G., \& Slade, T. (2001). Interpreting scores on the Kessler Psychological Distress Scale (K10). Australian and New Zealand Journal of Public Health, 25(6), 494-497. doi:10.1111/j.1467-842X.2001.tb00310.x

Archer, J. (2000). Sex differences in aggression between heterosexual partners: A meta-analytic review. Psychological Bulletin, 126(5), 651-680. doi:10.1037/0033-2909.126.5.651 
Australian Communications and Media Authority. (2015). Australians get mobile. Retrieved 19 October, 2015, from http://www.acma.gov.au/theACMA/engage-blogs/engage-blogs/ Research-snapshots/Australians-getmobile

Bland, R. C., Newman, S. C., Orn, H., \& Stebelsky, G. (1993). Epidemiology of pathological gambling in Edmonton. The Canadian Journal of Psychiatry, 38(2), 108-112. doi: $10.1177 / 070674379303800207$

Brasfield, H., Febres, J., Shorey, R., Strong, D., Ninnemann, A., Elmquist, J., Andersen, S. M., Bucossi, M., Schonbrun, Y. C., Temple, J. R., \& Stuart, G. L. (2012). Male batterers' alcohol use and gambling behavior. Journal of Gambling Studies, 28(1), 77-88. doi:10.1007/s10899-011-9246-0

Brasfield, H., Shorey, R., Febres, J., Strong, D., \& Stuart, G. L. (2011). Hazardous gambling among women court-mandated to batterer intervention programs. American Journal on Addictions, 20(2), 176-177. doi:10.1111/j.1521-0391.2010.00103.x

Capaldi, D. M., Knoble, N. B., Shortt, J. W., \& Kim, H. K. (2012). A systematic review of risk factors for intimate partner violence. Partner Abuse, 3(2), 1-27. doi:10.1891/19466560.3.2.e4

Crockford, D. N., \& el-Guebaly, N. (1998). Psychiatric comorbidity in pathological gambling: A critical review. Canadian Journal of Psychiatry, 43(1), 43-50. doi:10.1177/07067437 9804300104

Dowling, N. A., Cowlishaw, S., Jackson, A. C., Merkouris, S. S., Francis, K. L., \& Christensen, D. R. (2015). The prevalence of psychiatric comorbidity in treatment-seeking problem gamblers: A systematic review and meta-analysis. Australian and New Zealand Journal of Psychiatry, 49(6), 519-539. doi:10.1177/0004867415575774

Dowling, N. A., Jackson, A. C., Pennay, D. W., Francis, K. L., Pennay, A., \& Lubman, D. I. (2016). National estimates of Australian gambling prevalence: Findings from a dual-frame omnibus survey. Addiction, 111(3), 420-435. doi:10.1111/ add. 13176

Dowling, N. A., Jackson, A. C., Suomi, A., Lavis, T., KoziolMcLain, J., Thomas, S. A., Patford, J., Harvey, P., Battersby, M., Koziol-McLain, J., Abbott, M., \& Bellringer, M. E. (2014). Problem gambling and family violence: Prevalence and patterns in treatment-seekers. Addictive Behaviors, 39(12), 1713-1717. doi: 10.1016/j.addbeh.2014.07.00610.1016/j. addbeh.2014.07.006

Dowling, N. A., Merkouris, S. S., Greenwood, C. J., Oldenhof, E., Toumbourou, J. W., \& Youssef, G. J. (2017). Early risk and protective factors for problem gambling: A systematic review and meta-analysis of longitudinal studies. Clinical Psychology Review, 51, 109-124. doi:10.1016/j.cpr.2016.10.008

Dowling, N., Suomi, A., Jackson, A., Lavis, T., Patford, J., Cockman, S., Thomas, S., Bellringer, M., Koziol-Mclain, J., Battersby, M., Harvey, P., \& Abbott, M. (2016). Problem gambling and intimate partner violence: A systematic review and meta-analysis. Trauma Violence Abuse, 17(1), 43-61. doi: $10.1177 / 1524838014561269$

Echeburua, E., Gonzalez-Ortega, I., de Corral, P., \& Polo-Lopez, R. (2011). Clinical gender differences among adult pathological gamblers seeking treatment. Journal of Gambling Studies, 27(2), 215-227. doi:10.1007/s10899-010-9205-1

Enders, C. K. (2010). Applied missing data analysis. New York, NY: Guilford Publications.
Ferris, J., \& Wynne, H. (2001). The Canadian Problem Gambling Index: Final report. Ottawa, Canada: Canadian Centre on Substance Abuse.

Ford-Gilboe, M., Wathen, C. N., Varcoe, C., MacMillan, H. L., Scott-Storey, K., Mantler, T., Hegarty, K., \& Perrin, N. (2016). Development of a brief measure of intimate partner violence experiences: The Composite Abuse Scale (Revised)-Short Form (CASR-SF). BMJ Open, 6(12), e012824. doi:10.1136/ bmjopen-2016-012824

Goldstein, A. L., Walton, M. A., Cunningham, R. M., Resko, S. M., \& Duan, L. (2009). Correlates of gambling among youth in an inner-city emergency department. Psychology of Addictive Behaviors, 23(1), 113-121. doi:10.1037/a0013912

Jackson, A. C., Pennay, D., Dowling, N. A., Coles-Janess, B., \& Christensen, D. R. (2014). Improving gambling survey research using a dual-frame survey of landline and mobile phone numbers. Journal of Gambling Studies, 30(2), 291-307. doi:10.1007/s10899-012-9353-6

Lorenz, V. C., \& Shuttlesworth, D. (1983). The impact of pathological gambling on the spouse of the gambler. Journal of Community Psychology, 11(1), 67-76. doi:10.1002/1520-6629 (198301)11:1<67::AID-JCOP2290110107>3.0.CO;2-O

Kausch, O., Rugle, L., \& Rowland, D. Y. (2006). Lifetime histories of trauma among pathological gamblers. American Journal on Addictions, 15(1), 35-43. doi:10.1080/10550490500419045

Kessler, R., \& Mroczek, D. (1992). An update of the development of mental health screening scales for the US national health interview study [Memorandum]. Ann Arbor, MI: Survey Research Center of the Institute for Social Research.

Korman, L. M., Collins, J., Dutton, D., Dhayananthan, B., LittmanSharp, N., \& Skinner, W. (2008). Problem gambling and intimate partner violence. Journal of Gambling Studies, 24(1), 13-23. doi:10.1007/s10899-007-9077-1

Muelleman, R. L., DenOtter, T., Wadman, M. C., Tran, T. P., \& Anderson, J. (2002). Problem gambling in the partner of the emergency department patient as a risk factor for intimate partner violence. The Journal of Emergency Medicine, 23(3), 307-312. doi:10.1016/S0736-4679(02)00543-7

Palmer du Preez, K., Bellringer, M., Pearson, J., Dowling, N., Suomi, A., Koziol-McLain, J., Wilson, D., \& Jackson, A. (2018). Family violence in gambling help seeking populations. International Gambling Studies. Advance online publication. doi:10.1080/14459795.2018.1480648

Rabin, R. F., Jennings, J. M., Campbell, J. C., \& Bair-Merritt, M. H. (2009). Intimate partner violence screening tools: A systematic review. American Journal of Preventive Medicine, 36(5), 439-445.e4. doi:10.1016/j.amepre.2009.01.024

Raylu, N., \& Oei, T. (2009). Factors associated with the severity of gambling problems in a community gambling treatment agency. International Journal of Mental Health and Addiction, 7(1), 124-137. doi:10.1007/s11469-008-9160-6

Roberts, A., Coid, J., King, R., Murphy, R., Turner, J., BowdenJones, H., Du Preez, K. P., \& Landon, J. (2016). Gambling and violence in a nationally representative sample of UK men. Addiction, 111(12), 2196-2207. doi:10.1111/add.13522

Roberts, A., Sharman, S., Coid, J., Murphy, R., Bowden-Jones, H., Cowlishaw, S., \& Landon, J. (2017). Gambling and negative life events in a nationally representative sample of UK men. Addictive Behaviors, 75, 95-102. doi:10.1016/j.addbeh. 2017.07.002 
Rubin, D. B. (1987). Multiple imputation for nonresponse in surveys. Ottawa, Canada: Wiley.

Saunders, J. B., Aasland, O. G., Babor, T. F., De La Fuente, J. R., \& Grant, M. (1993). Development of the Alcohol Use Disorders Identification Test (AUDIT): WHO collaborative project on early detection of persons with harmful alcohol consumption-II. Addiction, 88(6), 791-804. doi:10.1111/j.1360-0443.1993.tb02093.x

Schluter, P. J., Abbott, M. W., \& Bellringer, M. E. (2008). Problem gambling related to intimate partner violence: Findings from the Pacific Islands families study. International Gambling Studies, 8(1), 49-61. doi:10.1080/14459790701870134

Scholes-Balog, K. E., Hemphill, S. A., Toumbourou, J. W., \& Dowling, N. A. (2015). Problem gambling and internalizing symptoms: A longitudinal analysis of common and specific social environmental protective factors. Addictive Behaviors, 46, 86-93. doi:10.1016/j.addbeh.2015.03.011

Sherin, K. M., Sinacore, J. M., Li, X. Q., Zitter, R. E., \& Shakil, A. (1998). HITS: A short domestic violence screening tool for use in a family practice setting. Family Medicine, 30(7), 508-512.

Slutske, W. S., Eisen, S., Xian, H., True, W. R., Lyons, M. J., Goldberg, J., \& Tsuang, M. (2001). A twin study of the association between pathological gambling and antisocial personality disorder. Journal of Abnormal Psychology, 110(2), 297-308. doi:10.1037/0021-843X.110.2.297

Suomi, A., Dowling, N. A., \& Jackson, A. C. (2014). Problem gambling subtypes based on psychiatric distress, alcohol abuse and impulsivity. Addictive Behaviors, 39(12), 1741-1745. doi:10.1016/j.addbeh.2014.07.023

Suomi, A., Dowling, N. A., Thomas, S., Abbott, M., Bellringer, M., Battersby, M., Koziol-McLain, J., Lavis, T., \& Jackson, A. C. (2018). Patterns of intimate partner violence and family violence in problem gambling. Psychology of Violence. Advance online publication. doi:10.1007/s10899018-9768-9

Suomi, A., Jackson, A., Dowling, N., Lavis, T., Patford, J., Thomas, S., Harvey, P., Abbott, M., Bellringer, M. E., Koziol-McLain, J., \& Cockman, S. (2013). Problem gambling and family violence: Family member reports of prevalence, family impacts and family coping. Asian Journal of Gambling Issues and Public Health, 3(1), 13-15. doi:10.1186/21953007-3-13

World Health Organization [WHO]. (2002). World report on violence and health: Summary. Geneva, Switzerland: World Health Organization.

World Health Organization [WHO]. (2006). Intimate partner violence and alcohol fact sheet. Geneva, Switzerland: World Health Organization.

World Health Organization ASSIST Working Group. (2002). The Alcohol, Smoking and Substance Involvement Screening Test (ASSIST): Development, reliability and feasibility. Addiction, 97(9), 1183-1194. doi:10.1046/j.1360-0443.2002. 00185.x 